\title{
Why patients do not attend cardiac rehabilitation: role of intentions and illness beliefs
}

Cardiothoracic

Department, $6^{\text {th }}$ Floor,

East Wing, St Thomas'

Hospital, Lambeth

Palace Road, London

SE1 7EH, UK

A Cooper

G Lloyd

G Jackson

Unit of Psychology,

Guy's, King's and St

Thomas' Medical

School, London

Bridge, London SE1

9RT, UK

J Weinman

Correspondence to:

Dr Jackson.

\author{
A Cooper, G Lloyd, J Weinman, G Jackson
}

\begin{abstract}
Objective-Many patients fail to attend cardiac rehabilitation. Attempts to identify sociodemographic or clinical predictors of non-attendance have not been very successful; therfore, this study aimed to determine whether the illness beliefs held during hospitalisation by patients who had suffered acute myocardial infarction or who had undergone coronary artery bypass graft surgery could predict cardiac rehabilitation attendance.
\end{abstract}

Subjects and methods-152 patients were prospectively studied of whom $41 \%$ had

8 February 1999

Table 1 Explanation of core illness beliefs

\begin{tabular}{ll}
\hline Illness representation & Beliefs regarding \\
\hline Identity (label for the disease) & Symptoms associated with the illness \\
Cause & Factors that have led to the illness \\
Timeline & Expected length of illness, may be acute, chronic or cyclical \\
Consequences & Expected outcome and subsequent effects \\
Control/cure & How the individual may help to control or cure their illness \\
\hline
\end{tabular}

Table 2 Main variables recorded by questionnaire

Patient baseline characteristics Age, sex, ethnicity, marital status, employment status

Risk profile assessment $\quad$ Body mass index, knowledge of blood pressure, total cholesterol concentration

Cardiac rehabilitation attendance Intention, attendance at six months

Illness perceptions

Timeline, control/cure, consequences, causal attribution to: lifestyle, stress

Evidence of angina/AMI/diagnosis of CHD 4 weeks or more before current hospital admission

AMI, acute myocardial infarction; CHD, coronary heart disease.

Table 3 Summary of patient baseline characteristics

\begin{tabular}{|c|c|c|c|c|}
\hline & Total population & $C A B G$ & $C A B G+A M I$ & $A M I$ \\
\hline Number & 137 & 42 & 31 & 64 \\
\hline Mean age (years) & 62.12 & 60.8 & 61.1 & 63.5 \\
\hline Confidence interval & 60.47 to 63.77 & 58.06 to 63.61 & 58.16 to 64.03 & 60.71 to 66.24 \\
\hline \multicolumn{5}{|l|}{ Sex } \\
\hline Male & $105(76.6 \%)$ & $38(90.5 \%)^{\star}$ & $23(74.2 \%)$ & $44(68.8 \%)$ \\
\hline Female & $32(23.4 \%)$ & $4(9.5 \%)$ & $8(25.8 \%)$ & $20(31.2 \%)$ \\
\hline \multicolumn{5}{|l|}{ Ethnicity } \\
\hline Caucasian & $122(89.1 \%)$ & $39(92.9 \%)$ & $26(83.9 \%)$ & $57(89.1 \%)$ \\
\hline Afro-Caribbean & $1(0.7 \%)$ & - & - & $1(1.6 \%)$ \\
\hline South Asian & $2(1.5 \%)$ & $1(2.4 \%)$ & $1(3.2 \%)$ & - \\
\hline Middle Eastern & $1(0.7 \%)$ & - & - & $1(1.6 \%)$ \\
\hline Chinese/Far Eastern & $1(0.7 \%)$ & - & $1(3.2 \%)$ & - \\
\hline Not stated & $10(7.5 \%)$ & $2(4.8 \%)$ & $3(9.7 \%)$ & $5(7.8 \%)$ \\
\hline \multicolumn{5}{|l|}{ Marital status } \\
\hline Single & $11(8.0 \%)$ & $3(7.1 \%)$ & $2(6.5 \%)$ & $6(9.4 \%)$ \\
\hline Married & $104(75.9 \%)$ & $32(76.2 \%)$ & $24(77.4 \%)$ & $48(75 \%)$ \\
\hline Divorced & $11(8.0 \%)$ & $3(7.1 \%)$ & $3(9.7 \%)$ & $5(7.8 \%)$ \\
\hline Widowed & $9(6.6 \%)$ & $2(4.8 \%)$ & $2(6.5 \%)$ & $5(7.8 \%)$ \\
\hline Not stated & $2(1.5 \%)$ & $2(4.8)$ & - & - \\
\hline \multicolumn{5}{|l|}{ Smoking history } \\
\hline Never & $37(27 \%)$ & $13(31 \%)$ & $9(29 \%)$ & $15(23.4 \%)$ \\
\hline Past & $87(63.5 \%)$ & $28(66.7 \%)$ & $19(61.3 \%)$ & $40(62.5 \%)$ \\
\hline Present & $11(8 \%)$ & - & $2(6.6 \%)$ & $9(14.1 \%)$ \\
\hline Not stated & $2(1.5 \%)$ & $1(2.7 \%)$ & $1(3.2 \%)$ & - \\
\hline \multicolumn{5}{|l|}{ Employment status } \\
\hline Employed & $51(37.2 \%)$ & $15(35.7 \%)$ & $14(45.2 \%)$ & $22(34.4 \%)$ \\
\hline Not employed (retired) & $85(62 \%)$ & $27(64.3 \%)$ & $17(54.8 \%)$ & $41(64.1 \%)$ \\
\hline Not stated & $1(0.7 \%)$ & - & - & $1(1.5 \%)$ \\
\hline
\end{tabular}

${ }^{\star} \mathrm{p}=0.03$

CABG, coronary artery bypass graft surgery; AMI, acute myocardial infarction. attended cardiac rehabilitation at six months.

Results-In addition to being older, less aware of their cholesterol values, and less likely to be employed, non-attenders were less likely to believe their condition was controllable and that their lifestyle may have contributed to their illness.

Conclusion-It should now be determined whether interventions aimed at optimising certain perceptions could promote cardiac rehabilitation uptake among those patients who could benefit the most.

(Heart 1999;82:234-236)

Keywords: rehabilitation; myocardial infarction; coronary artery bypass graft surgery; illness beliefs

Despite the established benefits of cardiac rehabilitation ${ }^{1-4}$ many patients either decline to attend or adhere poorly to courses. Petrie et al found that only a third of eligible patients under 65 years old attended cardiac rehabilitation, ${ }^{5}$ and Ades et al showed uptake as low as $21 \%$ in eligible patients over 62 years. ${ }^{6}$ The American Heart Association ${ }^{7}$ has emphasised the need to identify and focus on patients whose medical and social profiles predict noncompliance, since these patients may benefit most from specific interventions.

Not only are biological and sociodemographic characteristics inconsistently associated with non-attendance, the value of these as predictors is questionable given that they are not usually amenable to change. In contrast, individual's beliefs or perceptions about their illness appear to play a pivotal role in health behaviour including medication adherence, ${ }^{8}$ and functional status. ${ }^{9}{ }^{10}$ Furthermore a recent study emphasised the role of illness perceptions in predicting rehabilitation attendance, return to work, and physical functioning following acute myocardial infarction. ${ }^{5}$

The recently developed illness perception questionnaire (IPQ) is a validated measurement tool used by health psychologists to assess patients' beliefs about their illness. ${ }^{11}$ It has been established that beliefs are organised around straightforward and self explanatory central themes or components. These are referred to as "common sense illness representations"12 and are hypothesised to explain variations in the way patients respond to their illness (table 1).

We set out to determine whether the beliefs held during hospitalisation by patients who had suffered acute myocardial infarction or who had undergone coronary artery bypass graft surgery (CABG) could predict cardiac reha- 
Table 4 Differences in illness perceptions and risk factors between diagnostic categories

\begin{tabular}{llll}
\hline & $C A B G(n=42)$ & $C A B G+A M I(n=31)$ & $A M I(n=64)$ \\
\hline $\begin{array}{l}\text { Intention to go to } \\
\text { rehabilitation }\end{array}$ & $32(76.2 \%)$ & $23(74.2 \%)$ & $44(68.8 \%)$ \\
$\begin{array}{l}\text { Illness perceptions } \\
\quad \text { Control/cure }\end{array}$ & $24.3(23.2-25.4)$ & $24.9(23.4-26.3)$ & $23.5(22.7-24.2)$ \\
$\quad$ Consequences & $13.6(12.7-14.6)$ & $12.8(11.6-14.0)$ & $12.8(12.1-13.6)$ \\
$\quad$ Timeline & $9.3(8.5-10.1)$ & $9.9(8.8-11.0)$ & $9.9(9.2-10.7)$ \\
$\quad$ Causal attribution $\dagger$ & $3.2(2.8-3.6)$ & $3.4(3.0-3.9)$ & $3.2(2.8-3.4)$ \\
$\quad$ Lifestyle & $3.6(3.2-4.0)$ & $3.5(3.0-4.0$ & $3.3(3.0-3.7)$ \\
$\quad$ Stress & $36(85.7 \%)$ & $24(80 \%)$ & $49(76.6 \%)$ \\
Knowledge of BP & $33(78.6 \%)$ & $22(71 \%)$ & $23(35.9 \%)^{\star}$ \\
Knowledge of TC & $34(87.2 \%)$ & $26(83.9 \%)$ & $13(39 \%)^{\star}$ \\
$\begin{array}{l}\text { Previous history } \\
\text { Previous exercise }\end{array}$ & $21(58 \%)$ & $13(48.1 \%)$ & $29(50.9 \%)$ \\
\hline
\end{tabular}

Where count data are shown actual numbers are written with percentages shown in parentheses; for continuous data the mean score for each variable is shown with the confidence interval given in parentheses.

†Kruskall-Wallis test; ${ }^{\star} \mathrm{p}<0.001$

$\mathrm{BP}$, blood pressure; TC, total cholesterol.

bilitation attendance. The potential differences in illness beliefs between these two patient groups was also explored.

\section{Methods}

DESIGN AND PATIENT POPULATION

We conducted a prospective study involving 152 patients hospitalised for acute myocardial infarction or CABG. Consecutive patients were recruited to complete a questionnaire independently before discharge. Postal or telephone follow up assessed cardiac rehabilitation attendance at six months.

Patients who suffered acute myocardial infarction at two district general hospitals and

Table 5 Differences in baseline variables between attenders and non-attenders

\begin{tabular}{|c|c|c|c|}
\hline & Attenders $(n=55)$ & $\begin{array}{l}\text { Non-attenders } \\
(n=82)\end{array}$ & Significance \\
\hline Female & $10(18.2)$ & $22(26.8)$ & NS \\
\hline $\begin{array}{l}\text { Age (years) } \\
\text { Confidence interval } \\
\text { Range }\end{array}$ & $\begin{array}{l}58.4 \\
55.95 \text { to } 60.89 \\
39 \text { to } 77\end{array}$ & $\begin{array}{l}64.9 \\
62.55 \text { to } 66.71 \\
39 \text { to } 81\end{array}$ & $\mathrm{p}=0.0002$ \\
\hline Employed & $29(52.7)$ & $22(26.8)$ & $\mathrm{p}=0.007$ \\
\hline $\begin{array}{l}\text { Smoking history } \\
\text { Never } \\
\text { Past } \\
\text { Present }\end{array}$ & $\begin{array}{r}15(27.3) \\
34(61.8) \\
6(10.9)\end{array}$ & $\begin{array}{c}22(27.5) \\
53(66.3) \\
5(6.2)\end{array}$ & NS \\
\hline $\begin{array}{l}\text { Diagnosis } \\
\text { AMI } \\
\text { CABG } \\
\text { CABG + AMI }\end{array}$ & $\begin{array}{l}22(40) \\
20(36.4) \\
13(23.6)\end{array}$ & $\begin{array}{l}42(51.2) \\
22(26.8) \\
18(22)\end{array}$ & NS \\
\hline $\begin{array}{l}\text { Illness perceptions } \\
\text { Control/cure } \\
\text { Consequences } \\
\text { Timeline } \\
\text { Causal attribution } \\
\text { Lifestyle } \\
\text { Stress }\end{array}$ & $\begin{array}{c}24.9(24.0 \text { to } 25.8) \\
13.5(12.6 \text { to } 14.5) \\
9.8(8.9 \text { to } 10.6) \\
3.45(1.1) \dagger \\
3.6(1.1) \dagger\end{array}$ & $\begin{array}{c}23.4(22.7 \text { to } 24.1) \\
12.6(12.2 \text { to } 13.3) \\
9.8(9.2 \text { to } 10.4) \\
2.8(1.2) \dagger \\
3.3(1.3) \dagger\end{array}$ & $\begin{array}{l}\mathrm{p}=0.01 \\
\mathrm{p}=0.08 \\
\mathrm{NS} \\
\mathrm{p}=0.008 \\
\mathrm{NS}\end{array}$ \\
\hline Intention to attend & $51(92.7)$ & $48(58.5)$ & $\mathrm{p}=0.00001$ \\
\hline $\begin{array}{l}\text { Knowledge of } \\
\text { Blood pressure } \\
\text { Total cholesterol }\end{array}$ & $\begin{array}{l}45(81.8) \\
38(69.1)\end{array}$ & $\begin{array}{l}64(79) \\
40(48.8)\end{array}$ & $\begin{array}{l}\text { NS } \\
p=0.02\end{array}$ \\
\hline Previous regular exercise & $26(51.0)$ & $37(54)$ & NS \\
\hline Body mass index $\left(\mathrm{kg} / \mathrm{m}^{2}\right)$ & $25.8(24.4$ to 27.1$)$ & 25.7 (24.5 to 26.8$)$ & NS \\
\hline History of heart disease & $31(62)$ & $42(58.3)$ & NS \\
\hline
\end{tabular}

Where count data are given actual numbers are shown with percentages in parentheses; for continuous data the mean score for each variable is shown with the confidence intervals in parentheses.

${ }^{\star}$ Mann-Whitney U test; $† S D$.

NS, not significant. patients having CABG on the cardiothoracic ward at Guy's Hospital, London were enrolled. No exclusion criteria were set.

MAIN OUTCOME MEASUREMENTS

A binary and ordinal response questionnaire covering five areas was developed, details of which are listed in table 2 . Not all patients answered every question. Thus the figures given for certain items do not total 137 but reflect the number who responded to that item.

STATISTICAL ANALYSIS

SPSS for Windows 6.0 statistical software package was used throughout. Multiscore items of the IPQ were treated as continuous data and thus were analysed parametrically, using one way analysis of variance (ANOVA). Single item scores (causal attribution to lifestyle/stress) were treated non-parametrically and analysed using Mann-Whitney $U$ test. Frequency data were analysed using $\chi^{2}$ test. Variables predictive of cardiac rehabilitation attendance were analysed univariately to establish significant differences between attenders and non-attenders. Significant variables were entered into a forward stepwise logistic regression with attendance as the dependent variable.

\section{Results}

A total of 152 patients were recruited, with 15 exclusions as a result of four deaths and 11 uncompleted questionnaires. Summary patient baseline characteristics on the remaining 137 patients are shown in table 3. Not unexpectedly, those patients who had suffered acute myocardial infarction only were less likely to have a previous history of coronary artery disease than either CABG patients or those with both acute myocardial infarction and then CABG. Patients in the CABG and CABG/ acute myocardial infarction group were more likely to be male and to state an awareness of their total cholesterol concentrations.

Overall, $55(40 \%)$ patients attended rehabilitation with $82(60 \%)$ patients failing to attend by six months. There were no differences in illness perceptions or other sociodemographic variables between diagnostic groups (table 4) and all subjects were therefore combined to analyse potential differences between cardiac rehabilitation attenders and non-attenders. Table 5 shows the significant differences between the two groups; when these were entered into a logistic regression, age, perceptions of control, a causal attribution to lifestyle, and knowledge of total cholesterol concentration retained significance.

\section{Discussion}

Patients' illness beliefs were not influenced according to whether they had undergone CABG or acute myocardial infarction. One reason may be that patients diagnosed with coronary heart disease may establish firm beliefs about their illness at an early stage, perhaps because of the dominant prevalence of coronary heart disease in our society. Patients may draw on beliefs based on knowledge 
gained through media coverage and the experience of friends or colleagues which remain fairly stable over the varying course of their illness. ${ }^{13}$

The rehabilitation attendance rate of $40 \%$ is comparable with that reported in other studies ${ }^{5}{ }^{6}$ but falls short of the $72 \%$ of patients who expressed an intention to attend. The intention to attend rate in those actually attending cardiac rehabilitation was over $90 \%$ versus $58 \%$ for those not attending. This adds further weight to the evidence that intention alone is useful but not sufficient to predict future health behaviour. ${ }^{14}{ }^{15}$

Reliable predictors of attendance behaviour during hospital admission are necessary in order to optimise uptake in those who could benefit the most. This study shows that patient illness perceptions measured during hospital admission are associated with future cardiac rehabilitation attendance and that those with a stronger belief that their condition is controllable will subsequently take appropriate action such as attendance at cardiac rehabilitation. Similarly, individuals who attributed their heart condition to their lifestyle showed a higher rate of cardiac rehabilitation attendance indicating that this particular causal belief is associated with a commitment to further behaviour change. ${ }^{5}$

It may seem incongruent that knowledge of one risk factor, cholesterol, is associated with attendance while another, blood pressure, is not. However, individuals may feel that a high cholesterol is more relevant to heart disease than high blood pressure, which is perhaps perceived as quite common within the general population. In addition, patients may consider themselves to have more control over their cholesterol via dietary changes.

Few studies have investigated predictors of cardiac rehabilitation attendance, especially in relation to illness perceptions. It is encouraging that these results confirm those of a study of first time acute myocardial infarction patients under 65 years old where patients with a perception that their condition was controllable or curable were more likely to attend rehabilitation. ${ }^{5}$ Patient age may influence cardiac rehabilitation attendance but the identification of predictive illness perceptions may permit their modification to improve overall attendance and optimise outcome.

The 1996 UK cardiac rehabilitation guidelines and audit standards emphasise the importance of "addressing patients' main concerns and correcting misconceptions" throughout the rehabilitation phase from inhospital stay through to long term follow up. ${ }^{16}$ The IPQ could provide an ideal platform to determine an individual's illness perceptions as a routine part of recovery assessment. Illness perceptions have been shown to be amenable to change ${ }^{1017} 18$ in other illnesses; by providing information regarding illness perceptions in cardiac patients, simple individually structured interventions to address possible misconceptions could be developed. This may improve attendance in cardiac rehabilitation and additionally have a positive effect on other important outcome measures such as time to return to work and physical functioning.

We are grateful to all physiotherapy and cardiac rehabilitation staff, especially Jackie Anderson, Lesley Brooks, Sarah Deacon, Gilly Fumicelli, Sam Healy, Lynn Kilner, Lynne Schofield, Sally Stone, and Kate Street, for their enthusiastic help with this Stone,
study.

1 O'Connor GT, Buring JE, Yusef S, et al. An overview of randomised trials of rehabilitation with exercise after myocardomised trials of rehabilitation with exercise
dial infarction. Circulation 1989;80:234-44.

2 Linden W, Stossel C, Maurice J. Psychosocial interventions for patients with coronary artery disease. Arch Intern Med 1996;156:745-52.

3 Oldridge NB, Guyatt G, Fischer M, et al. Cardiac rehabilitation after myocardial infarction: combined experience of randomized clinical trials. $\mathscr{f} A M A$ 1988;260:945-50

4 Lau J, Antman E, Jimenez-Silva J, et al. Cumulative meta-analysis of therapeutic trials for myocardial infarction. N Engl f Med 1992;327:248-54.

5 Petrie KJ, Weinman J, Sharpe N, et al. Predicting return to work and functioning following myocardial infarction: the role of the patient's view of their illness. BMF 1996;312: 1191-4.

6 Ades PA, Waldman ML, McCann WJ, et al. Predictors of cardiac rehabilitation participation in older coronary patients. Arch Intern Med 1996;152:1033-5.

7 American Heart Association Writing Group. Cardiac rehabilitation programmes, a statement of healthcare rehabilitation programmes, a statement of healthcare
professionals from the American Heart Association. Circuprofessionals from the Am

8 Horne R. Representations of medication and treatment: advances in theory and measurement. In: Petrie K, Weinman J, eds. Perceptions of illness and health: current research and applications. London: Harwood Academic, 1997:155-87.

9 Pimm T. Self regulation and psycho-educational interventions for rheumatic disease. In: Petrie K, Weinman J, eds. Perceptions of illness and health: current research and applications. London: Harwood Academic, 1997:349-77.

10 Pimm T, Byron MA, Amos M. Coping with rheumatoid arthritis: a pilot study of the therapeutic benefit of a self manement intervention [abstract]. Scand $\mathcal{F}$ Rheumatol 1994;97(suppl): 114

11 Weinman J, Petrie KJ, Moss-Morris R, et al. The illness perception questionnaire: a new method for assessing the cogception questionnaire: a new method for assessing the cog-
nitive representation of illness. Psychology and Health 1996; 11:431-45.

12 Leventhal H, Meyer D, Nerenz D. The common sense representation of illness danger. In: Rachman S, ed. Contributions to medical psychology. New York: Pergamon Press, 1980:17-30

13 Petrie KJ, Weinman J. Illness representations and recovery from myocardial infarction. In: Petrie K, Weinman J. Perceptions of health and illness: current research and applications. London: Harwood Academic, 1997:441-61.

14 Leventhal H, Trembly G. Negative emotions and persuasion. F Pers 1968;36:154-68.

15 Leventhal H, Singer R, Jones S. Effects of fear and specificity of recommendations upon attitudes and behavior. F Pers Soc Psychol 1965;2:20-9.

16 Thompson DR, Bowman GS, Kitson AL, et al. Cardiac rehabilitation in the United Kingdom:guidelines and audit standards. Heart 1996;75:89-93.

17 Pimm TJ, Byron MA, Curson D, et al. Personal illness models and the self-management of arthritis [abstract]. Arthritis els and the self-managem

18 Johnston M, Gilbert P, Partridge C, et al. Changing perceived control in patients with physical disabilities: an intervention study with patients receiving rehabilitation. $\mathrm{Br}$ f Clin Psychol 1992;31:89-94. 